\title{
Video Article \\ Inhibitory Synapse Formation in a Co-culture Model Incorporating GABAergic Medium Spiny Neurons and HEK293 Cells Stably Expressing GABA Receptors
}

\author{
Laura E. Brown ${ }^{1}$, Celine Fuchs ${ }^{1}$, Martin W. Nicholson ${ }^{1}$, F. Anne Stephenson ${ }^{1}$, Alex M. Thomson ${ }^{1}$, Jasmina N. Jovanovic ${ }^{1}$ \\ ${ }^{1} \mathrm{UCL}$ School of Pharmacy, University College London
}

Correspondence to: Jasmina N. Jovanovic at j.jovanovic@ucl.ac.uk

URL: https://www.jove.com/video/52115

DOI: doi: $10.3791 / 52115$

Keywords: Neuroscience, Issue 93, Developmental neuroscience, synaptogenesis, synaptic inhibition, co-culture, stable cell lines, GABAergic, medium spiny neurons, HEK 293 cell line

Date Published: $11 / 14 / 2014$

Citation: Brown, L.E., Fuchs, C., Nicholson, M.W., Stephenson, F.A., Thomson, A.M., Jovanovic, J.N. Inhibitory Synapse Formation in a Co-

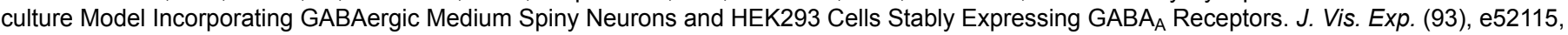
doi:10.3791/52115 (2014).

\section{Abstract}

Inhibitory neurons act in the central nervous system to regulate the dynamics and spatio-temporal co-ordination of neuronal networks. GABA ( $\gamma$ aminobutyric acid) is the predominant inhibitory neurotransmitter in the brain. It is released from the presynaptic terminals of inhibitory neurons within highly specialized intercellular junctions known as synapses, where it binds to $G_{A B A}$ receptors $\left(G A B A_{A} R s\right)$ present at the plasma membrane of the synapse-receiving, postsynaptic neurons. Activation of these GABA-gated ion channels leads to influx of chloride resulting in postsynaptic potential changes that decrease the probability that these neurons will generate action potentials.

During development, diverse types of inhibitory neurons with distinct morphological, electrophysiological and neurochemical characteristics have the ability to recognize their target neurons and form synapses which incorporate specific $G_{A B A} R_{A}$ subtypes. This principle of selective innervation of neuronal targets raises the question as to how the appropriate synaptic partners identify each other.

To elucidate the underlying molecular mechanisms, a novel in vitro co-culture model system was established, in which medium spiny GABAergic neurons, a highly homogenous population of neurons isolated from the embryonic striatum, were cultured with stably transfected HEK293 cell lines that express different $\mathrm{GABA}_{\mathrm{A}} \mathrm{R}$ subtypes. Synapses form rapidly, efficiently and selectively in this system, and are easily accessible for quantification. Our results indicate that various $\mathrm{GABA}_{\mathrm{A}} \mathrm{R}$ subtypes differ in their ability to promote synapse formation, suggesting that this reduced in vitro model system can be used to reproduce, at least in part, the in vivo conditions required for the recognition of the appropriate synaptic partners and formation of specific synapses. Here the protocols for culturing the medium spiny neurons and generating HEK293 cells lines expressing $\mathrm{GABA}_{A} \mathrm{Rs}$ are first described, followed by detailed instructions on how to combine these two cell types in co-culture and analyze the formation of synaptic contacts.

\section{Video Link}

The video component of this article can be found at https://www.jove.com/video/52115/

\section{Introduction}

GABA is one of the earliest neurotransmitters found in the embryonic brain, preceding the most abundant excitatory neurotransmitter glutamate ${ }^{1}$. During development, GABA depolarizes and excites immature neurons, playing a key role in regulating cell proliferation, migration and formation of neuronal networks without inducing excitotoxicity. In the adult brain, the reversal potential for $\mathrm{GABA}_{A}$ receptor channels is shifted to more negative potentials due to a decrease in the intracellular concentration of chloride. This shift is caused by up-regulation of the potassium-chloride co-transporter (KCC2), which transports chloride out of the cell, and, in parallel, down-regulation of the sodium-potassium-chloride transporter (NKCC1), which has the opposite effect ${ }^{2}$.

In the brain, GABA primarily binds to either $\mathrm{GABA}_{A}$ or $\mathrm{GABA}_{B}$ receptors to mediate fast or slow synaptic inhibition, respectively. $G A B A_{A} R s$ are a class of receptors also known as heteropentameric ionotropic or ligand-gated Cys-loop ion channels. Two molecules of GABA are required for activation of the receptor, which is permeable to chloride ions and to a lesser degree, bicarbonate ions. The increase in chloride conductance decreases the effectiveness of depolarizing, excitatory events in activating the postsynaptic neuron ${ }^{3}$.

Structural diversity of $\mathrm{GABA}_{A}$ Rs has long been recognized as a key factor in determining their wide range of functional and pharmacological properties. Native $\mathrm{GABA}_{A}$ Rs are hetero-pentamers composed of subunits with multiple isoforms classified as: $\alpha(1-6), \beta(1-3), \gamma(1-3), \delta, \varepsilon, \pi$ and $\theta^{3}$, with a common transmembrane topology comprising a large $\mathrm{N}$-terminal extracellular domain, four transmembrane domains (TMs), and a major intracellular domain between TMs 3 and $4^{4}$. The $\beta 3$ and $\gamma 2$ subunits are essential for synaptic inhibition and organism survival, because mice bearing genetic deletion of these subunits die after birth ${ }^{5,6}$. In contrast, individual isoforms of $\alpha$ subunit are important for the function of specific synaptic connections in the brain associated with different behaviors such as anxiety, sedation, arousal, and others, but are 
not, individually, essential for life ${ }^{7-9}$. GABA $\mathrm{A}_{\mathrm{R}}$ are the main sites of action for a variety of drugs with potent sedative, hypnotic, anxiolytic and anticonvulsant effects, such as benzodiazepines, barbiturates, neurosteroids and anesthetics ${ }^{7,10,11}$.

Synaptic GABA ${ }_{A}$ Rs typically contain a $2^{2}$ subunit, two $\beta$ subunits (most commonly $\beta 2$ or $\beta 3$ ) and two $\alpha$ subunits $(\alpha 1, \alpha 2, \alpha 3 \text { or } \alpha 5)^{12,13}$. The predominant class of extra-synaptic receptors contains the $\delta$ subunit in combination with two $\alpha$ subunits ( $\alpha 4$ or $\alpha 6$ ), and two $\beta$ subunits ( $\beta 2$ or $\beta 3)^{14}$. Subcellular localization of $\mathrm{GABA}_{A}$ Rs to axons, dendrites or soma, and insertion into the plasma membrane are dependent on the presence of $\beta$-subunits ${ }^{15,16}$. However, selective incorporation of different $G_{A B A} R$ subtypes into distinct types of synapses correlates well with the presence of specific $\alpha$ subunits $(\alpha 1, \alpha 2, \alpha 3 \text { or } \alpha 5)^{7,17,18}$. Importantly, deletion of $\alpha 1$ or $\alpha 2$ subunit in mice causes ultrastructural changes at inhibitory synapses ${ }^{19}$. This suggests that $\mathrm{GABA}_{\mathrm{A}} \mathrm{Rs}$ themselves may play a direct role in regulating synapse formation.

Evidence indicates that GABAergic synapse development is a precisely co-ordinated sequence of events, in which both the neuronal targets contacted by different types of inhibitory axons and the receptors that are clustered at each class of inhibitory synapse are selective and functionally attuned ${ }^{17,20-22}$. This fundamental principle of specificity at GABAergic synapses raises the question as to how the pre- and postsynaptic partners recognize each other during the initiation of synaptic contacts.

In vitro co-culture assays have been applied successfully to study some of the mechanisms of synapse formation and to test the role of individual synaptic cleft-spanning proteins in this process. One of the common trans-synaptic interacting protein combinations that function bi-directionally to mediate synapse formation and maturation, are the Neurexins (Nrxns) and Neuroligins (NLs). Nrxns are presynaptic proteins that exhibit alternative splicing within their laminin-neurexin-sex hormone-binding protein domains, giving rise to many different isoforms ${ }^{23}$. While the Nrxns also interact with other proteins, NLs are thought to be their ubiquitous postsynaptic partners ${ }^{24}$. Together these proteins contribute to holding the presynaptic and postsynaptic membranes in close and rigid apposition ${ }^{25}$. The two most abundant isoforms are NL-1 and NL-2 which are present at excitatory and inhibitory synapses, respectively ${ }^{26}$. One of the earliest co-culture model systems, designed to investigate trans-synaptic protein interactions, employed different types of non-neuronal cells, most commonly immortal cell lines such as Human Embryonic Kidney (HEK) 293 cells, to over-express NL-2. When these cells were cultured with pontine neurons, an accumulation of presynaptic proteins in close proximity to the surface of the HEK cells was observed, indicating formation of synapse-like contacts. Addition of soluble $\beta$-neurexin to these co-cultures inhibited the formation of contacts, suggesting that trans-synaptic interactions between Nrxns and NLs are necessary for synaptic contact formation $^{27}$. Moreover, transient expression of $\beta$-neurexin in COS (CV-1 (simian) in Origin, and carrying the SV40 genetic material) cells co-cultured with dissociated hippocampal glutamatergic and GABAergic neurons induced expression of the postsynaptic protein gephryin and of $\mathrm{GABA}_{A} R$ subunits $\gamma 2$ and $\alpha 2$ at points of contact between these two cells types ${ }^{28}$. Another example of a co-culture model used to study synapse formation involved HEK293 cells, transiently transfected with $\mathrm{GABA}_{\mathrm{A}} R$ subunits $\alpha 2 / \beta 3 / \mathrm{\gamma} 2$ and NL-2, and a mixed population of hypothalamic neurons $^{29}$. This study concluded that the expression of NL-2 is an absolute requirement for formation of inhibitory synapses.

However, in the recent co-culture study, stably transfected $\alpha 1 / \beta 2 / \gamma 2 G A B A_{A} R$ s in HEK293 cells were found to be sufficient to induce functional synapses when co-cultured with GABAergic medium spiny neurons, without the need for additional trans-synaptic or postsynaptic adhesion proteins. However, a prominent increase in synapse formation and strength was observed when NL-2 was co-expressed with $\mathrm{GABA}_{\mathrm{A}} \mathrm{Rs}^{30}$. This indicates that this co-culture model system has advantages over previously described model systems, most evidently an increased sensitivity and reliability of synaptic contact detection. Two important factors contributing to the overall improvement in detection of synaptic contacts are: i) The use of stably transfected HEK293 cell lines with high and consistent expression of $G_{A B A} R$ subunits at the surface of individual cells. This consistency facilitates quantitative comparisons between different co-culture conditions. ii) The use of a pure population of GABAergic medium spiny neurons cultured from the embryonic striatum ${ }^{31}$ removes complications and ambiguities resulting from the use of mixed neuronal populations and allows, for example, selection of the most appropriate postsynaptic $G_{A B A} R$ types that can be compared with each other during synapse formation.

Formation of synapses is thought to involve many trans-synaptic signals within pre- and postsynaptic cell adhesion complexes. Due to the bidirectional nature of synaptic signaling and the sheer numbers of cell adhesion molecules, it is difficult to identify key components involved in synapse formation. Thus, transfecting a single cell adhesion protein into a non-neuronal cell (in this case, the two most prevalent postsynaptic targets for GABAergic medium spiny neurons in vivo, $\alpha 1 / \beta 2 / \gamma 2$ or $\alpha 1 / \beta 3 / \gamma^{2} \mathrm{GABA}_{\mathrm{A}} \mathrm{Rs}^{32}$ ) greatly reduces the complexity of trans-synaptic signals available at the postsynaptic surface and allows precise quantitative analysis of the efficacy of this protein in promoting synapse formation.

Protocol

Sprague-Dawley rats or BAB/c inbred mice (Harlan, UK; the number of pregnant females used was 30) were housed and sacrificed according to UK Home Office [and European Communities Council directive of 24 November 1986 (86/609/EEC)] guidelines. The project was formally approved by the UCL School of Pharmacy Ethics Committee.

\section{Preparation of Instruments, Culture Medium, and Dishes}

1. Turn on and clean the laminar flow hood with $70 \%$ ethanol in order to work under sterile conditions at all times.

2. Prepare HEK293 cell culture medium, containing Dulbecco's Modified Eagle Medium pH 7.4 (DMEM, 500 ml), L-glutamine (2 mM), penicillin (50 Units $/ \mathrm{ml})$, streptomycin $(50 \mu \mathrm{g} / \mathrm{ml})$, and fetal bovine serum $(10 \%)$. NOTE: penicillin and streptomycin are irritants.

3. Prepare the serum-free neuronal culture medium, containing Neurobasal medium pH 7.4 (500 ml), B27 supplement (25 ml), L-glutamine (2 $\mathrm{mM})$, penicillin (50 Units $/ \mathrm{ml})$, streptomycin $(50 \mu \mathrm{g} / \mathrm{ml})$, and glucose $(6 \mathrm{mM})$.

4. Prepare $500 \mathrm{ml}$ of HEPES-buffered saline solution (HBSS), containing HBSS 10x stock (50 ml), HEPES (1 M) (5 ml) and water (445 ml), pH 7.4 .

5. Autoclave phosphate buffered saline solution (PBS, $\mathrm{pH} 7.4 ; 1 \mathrm{~L})$, water $(1 \mathrm{~L})$, glass coverslips (13 mm in diameter) and glass Pasteur pipettes to sterilize them. 


\section{Preparation of HEK293 Stable Cell Line Expressing $\alpha 1 / \beta 3 / y 2-G A B A_{A} R s$}

1. Plate $2 \times 10^{6} \mathrm{HEK} 293$ cells into a $10 \mathrm{~cm}$ sterile tissue culture plate and incubate at $37{ }^{\circ} \mathrm{C}$ in a humidified $5 \%$ carbon dioxide $\left(\mathrm{CO}_{2}\right)$ atmosphere $\left(\mathrm{CO}_{2}\right.$ incubator) in order to reach $70-90 \%$ confluency overnight.

2. The following day, transfect HEK293 cells with $G A B A_{A} R \alpha 1$ subunit cDNA in the pcDN $3.1^{(+)}$expression vector incorporating the G418 disulfate (Table 1) resistance gene, and the GABA $R$ R3 subunit $c D N A$ in the expression vector incorporating the phleomycin D1 (Table 1) resistance gene (both under the regulation of a human cytomegalovirus immediate-early (CMV) promoter), using a cationic liposome formulation, which complexes with negatively charged nucleic acid molecules (Table 1) according to manufacturer's protocol.

3. Briefly, add $500 \mu \mathrm{l}$ of reduced serum medium ( $\mathrm{pH} 7.4$; Table 1 ) and $7.5 \mu \mathrm{g}$ of each cDNA construct to a sterile $15 \mathrm{ml}$ centrifuge tube, followed by $15 \mu \mathrm{l}$ of liposomal transfection buffering reagent, and gently mix before leaving at room temperature for 5 min.

4. To this mixture, add $8.75 \mu \mathrm{l}$ of liposomal transfection reagent and gently mix before leaving at room temperature for $30 \mathrm{~min}$. Following this, add $3 \mathrm{ml}$ of HEK293 cell culture medium (without antibiotics), pipette the contents of the centrifuge tube up and down twice, transfer drop-wise onto the cells growing in a $10 \mathrm{~cm}$ tissue culture dish, and incubate for $48 \mathrm{hr}$ at $37{ }^{\circ} \mathrm{C}$ in a humidified $5 \% \mathrm{CO}_{2}$ atmosphere $\left(\mathrm{CO}_{2}\right.$ incubator).

5. Wash the HEK293 cells gently with sterile PBS, pH 7.4, and dilute the transfected HEK293 cells into new $10 \mathrm{~cm}$ tissue culture dishes, in the following ratios: 1:3,1:5, 1:7, 1:10,1:15 and 1:20. This ensures that the cells will not become overly confluent.

6. Start selection of the HEK293 cells expressing both $\mathrm{GABA}_{A} \mathrm{R}$ subunits by adding $800 \mu \mathrm{g} / \mathrm{ml}$ of each antibiotic selection marker, G418, and Phleomycin D1, to the culture medium. Incubate the cells at $37{ }^{\circ} \mathrm{C}$ in a humidified $5 \% \mathrm{CO}_{2}$ atmosphere $\left(\mathrm{CO}_{2}\right.$ incubator $)$ and replace the antibiotic-containing medium $(10 \mathrm{ml})$ every 2 days.

7. When small white colonies start to form (usually after about 7 days), carefully select a single colony from each of the dishes and collect it using a sterile P1000 pipette tip. Transfer it to one well of a 24-well tissue culture plate containing $500 \mu l$ of medium and carefully resuspend by pipetting the medium up and down. Ensure that exactly one colony is transferred into each well (a total of 5-20 colonies is advised). Incubate the cells at $37{ }^{\circ} \mathrm{C}$ in a humidified $5 \% \mathrm{CO}_{2}$ atmosphere $\left(\mathrm{CO}_{2}\right.$ incubator) and replace the antibiotic-containing medium every 2 days.

8. Once the colonies become $70-80 \%$ confluent, gently pipette the medium up and down to dislodge the cells from the bottom of the 24 -well tissue culture plate. Transfer and divide the suspension of cells between 2 wells in a 6 -well tissue culture plate. Incubate the cells at $37{ }^{\circ} \mathrm{C}$ in a humidified $5 \% \mathrm{CO}_{2}$ atmosphere $\left(\mathrm{CO}_{2}\right.$ incubator) and replace the antibiotic-containing medium every 2 days.

9. Once $70-80 \%$ confluent, collect the cells from 1 of the 2 wells containing the cells originating from the same single colony and prepare protein lysates. Briefly, wash the cells $2 x$ with PBS, pH 7.4, and add $200 \mu$ of $2 \%$ sodium dodecyl sulfate (SDS) in PBS, pH 7.4. Collect the lysate and transfer it to the microcentrifuge tube. Measure the protein concentration using BCA protein reagent (see Table 1) according to the manufacturer's protocol. Analyze the expression of $\alpha 1$ and $\beta 3$ subunits of GABA $A_{A}$ receptors by SDS/PAGE and immunoblotting using subunit-specific antibodies (rabbit anti- $\alpha 1$-specific and rabbit anti- $\beta 3$-specific $G A B A_{A} R$ antibodies, see Table 1 for the information on these antibodies).

10. Dislodge and transfer only positive clones from the remaining wells to larger $6 \mathrm{~cm}$ tissue culture dishes. Incubate the cells at $37^{\circ} \mathrm{C}$ in a humidified $5 \% \mathrm{CO}_{2}$ atmosphere $\left(\mathrm{CO}_{2}\right.$ incubator) and replace the antibiotic-containing medium every 2 days.

11. Gradually expand the colonies of cells under the antibiotic selection by transferring them to $10 \mathrm{~cm}$ tissue culture dishes and finally to tissue culture flasks (T-75 flasks). Incubate the cells at $37^{\circ} \mathrm{C}$ in a humidified $5 \% \mathrm{CO}_{2}$ atmosphere $\left(\mathrm{CO}_{2}\right.$ incubator) and replace the antibioticcontaining medium every 2 days.

12. Plate 70,000 cells from each colony on glass coverslips ( $13 \mathrm{~mm}$ in diameter) and fix the cells to analyze the cell surface expression and colocalization of $\mathrm{GABA}_{\mathrm{A}} \mathrm{R}$ subunits by immunofluorescence.

13. Select the positive clone of HEK293 cells expressing high levels of both $\alpha 1$ and $\beta 3$ subunits of GABA $A_{A}$ receptors, plate $2 \times 10^{6}$ cells into a 10 $\mathrm{cm}$ sterile tissue culture dish and incubate at $37{ }^{\circ} \mathrm{C}$ in a humidified $5 \% \mathrm{CO}_{2}$ atmosphere $\left(\mathrm{CO}_{2}\right.$ incubator) overnight. Ensure that the cells are incubated in antibiotic-containing (G418 and Phleomycin D1) medium at all times.

14. The following day, transfect HEK293 cells with $G A B A_{A} R$ $Y 2 s$ subunit $c D N A$ in the pcDNA ${ }^{T M} 3.1^{(+)}$expression vector incorporating Hygromycin $B$ resistance gene using a non- liposomal lipid transfection reagent (Table 1).

NOTE: This transfection method allows better survival and higher expression efficiency of foreign proteins in slow growing stable cell lines which are under continuous selection with antibiotics.

15. In a sterile $15 \mathrm{ml}$ centrifuge tube, add $250 \mu \mathrm{l}$ of Enhancer and DNA condensation buffer (Table 1) and $1.4 \mu \mathrm{g}$ of $\mathrm{Y}^{\mathrm{s}} \mathrm{s} \mathrm{GBA}_{\mathrm{A}}$ receptor subunit cDNA. Add $11.2 \mu \mathrm{l}$ of Enhancer and vortex for $1 \mathrm{sec}$ before leaving at room temperature for $5 \mathrm{~min}$.

16. Add $35 \mu \mathrm{l}$ of non-liposomal lipid transfection reagent and vortex for $10 \mathrm{sec}$ before leaving at room temperature for $10 \mathrm{~min}$. Add $3 \mathrm{ml}$ of $\mathrm{G} 418$ / Phleomycin D1-containing medium and pipette the content of the centrifuge tube up and down twice before transferring it drop-wise onto the cells growing in a $10 \mathrm{~cm}$ tissue culture plate. Incubate the cells for $48 \mathrm{hr}$ at $37^{\circ} \mathrm{C}$ in a humidified $5 \% \mathrm{CO}_{2}$ atmosphere $\left(\mathrm{CO}_{2}\right.$ incubator).

17. Wash the cells gently with sterile PBS and dilute them into new $10 \mathrm{~cm}$ tissue culture dishes, in the following ratios: 1:3, 1:5, 1:7, 1:10, $1: 15$ and 1:20.

18. Start selection of $\alpha 1 / \beta 3-H E K 293$ cells expressing the $\gamma 2 s$ subunit by adding $800 \mu \mathrm{g} / \mathrm{ml}$ of antibiotic selection marker Hygromycin B to the G418/Phleomycin D1-containing medium. Replace the old medium with the fresh G418/Phleomycin D1/Hygromycin B-containing medium (10 $\mathrm{ml}$ ) every 2 days.

19. Repeat steps 2.7-2.12, under continuous selection in G418/Phleomycin D1/Hygromycin B-containing cell culture medium.

20. Store the positive clones at $-140{ }^{\circ} \mathrm{C}$ in antibiotic-free cell culture medium and $10 \%$ dimethyl sulfoxide (DMSO) for the future use.

21. Test the level of expression of $\alpha 1, \beta 3$ and $\gamma 2 s G A B A_{A} R$ subunits by immunoblotting and immunofluorescence in each clone following defrosting, because the expression can change due to reduced survival of cells under antibiotic selection.

\section{Maintenance of HEK293 Cell Lines}

1. Defrost a vial of control HEK293 cells or those expressing either $\alpha 1 / \beta 2 / \gamma 2-G A B A_{A} R s$ (Table 1 ) or $\alpha 1 / \beta 3 / \gamma 2-G A B A_{A} R s$ (described above) into $10 \mathrm{ml}$ of cell culture medium in a $15 \mathrm{ml}$ sterile centrifuge tube. Centrifuge at $440 \times \mathrm{g}$ for $5 \mathrm{~min}$ to remove excess DMSO.

2. Remove supernatant and resuspend cells in $1 \mathrm{ml}$ of fresh cell culture medium.

3. First add $9 \mathrm{ml}$ of fresh cell culture medium to a $10 \mathrm{~cm}$ tissue culture dish coated with poly-D-lysine $(0.1 \mathrm{mg} / \mathrm{ml})$ and then $1 \mathrm{ml}$ of resuspended cells. Agitate gently, side-to-side, to disperse the cells and incubate at $37{ }^{\circ} \mathrm{C}$ in a humidified $5 \% \mathrm{CO}_{2}$ atmosphere $\left(\mathrm{CO}_{2}\right.$ incubator). 
4. The following day, aspirate the medium to remove any cell debris and replace with $10 \mathrm{ml}$ of fresh HEK293 cell culture medium.

5. Select stable cell lines with antibiotics to remove any cells which do not express $G A B A_{A} R$ subunits and therefore also lack the expression of antibiotic resistance markers. For the $\alpha 1 / \beta 2 / \gamma 2$ stable cell line, replace normal medium with fresh cell culture medium containing G418 $(800 \mu \mathrm{g} / \mathrm{ml})$. For the $\alpha 1 / \beta 3 / \mathrm{\gamma} 2$ cell line, replace with fresh cell culture medium containing $\mathrm{G} 418(800 \mu \mathrm{g} / \mathrm{ml})$, Phleomycin D1 (800 $\mu \mathrm{g} / \mathrm{ml})$ and Hygromycin B $(800 \mu \mathrm{g} / \mathrm{ml})$. CAUTION! G418 is an irritant and Hygromycin B is corrosive, toxic and an irritant.

6. Passage the cells into a new tissue culture dish by seeding at a lower density once they achieve $>70 \%$ confluency. Aspirate $10 \mathrm{ml}$ of cell culture medium and wash twice briefly with PBS, pH 7.4. Add $1 \mathrm{ml}$ of trypsin-EDTA solution, a solution of the protease trypsin (0.05\% trypsin) and a $\mathrm{Ca}^{2+}$ chelator EDTA $(0.02 \%)$ in PBS, $\mathrm{pH} 7.4$, to detach the cells from the dish. CAUTION! Trypsin-EDTA solution is an irritant.

7. Add $10 \mathrm{ml}$ of cell culture medium containing the correct antibiotics, to the dish and aspirate the cells. Centrifuge the cells at $440 \times \mathrm{g}$ for $5 \mathrm{~min}$ and resuspend them in $5 \mathrm{ml}$ of the cell culture medium.

8. Passage the cells using a 1:10 dilution into a new tissue culture flask (T-75 flask) containing fresh cell culture medium and the correct antibiotics. Incubate the cells at $37^{\circ} \mathrm{C}$ in a humidified $5 \% \mathrm{CO}_{2}$ atmosphere $\left(\mathrm{CO}_{2}\right.$ incubator $)$ and replace the medium every two days. Passage the cells when $>70 \%$ confluent (see step 2.8).

\section{Preparation of GABAergic Medium Spiny Neuron Culture}

1. Under sterile conditions prepare a 24 -well plate with poly-L-lysine $(0.1 \mathrm{mg} / \mathrm{ml})$-coated coverslips $\left(13 \mathrm{~mm}\right.$ in diameter) and incubate at $37{ }^{\circ} \mathrm{C}$ in a humidified $5 \% \mathrm{CO}_{2}$ atmosphere $\left(\mathrm{CO}_{2}\right.$ incubator).

2. The following day, aspirate with a pipette the excess poly-L-lysine and wash coverslips with two brief 10 sec and two 5 min long washes with sterile water. Add laminin $(0.01 \mathrm{mg} / \mathrm{ml})$ overnight and incubate at $37^{\circ} \mathrm{C}$ in a humidified $5 \% \mathrm{CO}_{2}$ atmosphere $\left(\mathrm{CO}_{2}\right.$ incubator).

3. Sanitize the dissection area with $70 \%$ ethanol and gather an array of dissecting tools such as curved and straight tissue forceps, scissors and tweezers, and place into $70 \%$ ethanol to fully sterilize the dissecting instruments.

4. Place the pregnant rat/mouse euthanized with $\mathrm{CO}_{2}$ on its back and clean the skin on its abdomen with $70 \%$ ethanol. Pinch the skin with tweezers and cut around the abdomen through the skin, muscle and peritoneum, to reveal the internal organs and uterus with embryos clearly. Extract the embryos (E16-17) from the uterus and place them in a Petri dish with chilled PBS.

5. Place the embryos in the laminar flow hood and decapitate them, collecting the heads in a new Petri dish with chilled HBSS.

6. Under a dissecting microscope, dissect out the brains using the curved and straight forceps. Place the brains into a new Petri dish containing chilled HBSS.

7. Separate the two cerebral hemispheres and carefully remove the meninges. Cut along the line of the hippocampus and peel back the cortex to reveal the striatum. Observe the striatum as a striated white structure at the anterior of the hemisphere.

8. Dissect the striatum and cut it into very small pieces (1 - $2 \mathrm{~mm}$ in diameter) and use a fire-polished Pasteur pipette to collect the material into a sterile $15 \mathrm{ml}$ centrifuge tube with a total volume of $1 \mathrm{ml}$. Fire-polishing ensures the material is collected without being damaged.

9. Using the fire-polished tip of the Pasteur pipette, aspirate the cells and release them $8-10$ times. Taking a new pipette with a fire-polish tip of approximately $30 \%$ of its original diameter $(1 \mathrm{~mm})$, triturate the solution a further $4-6$ times until it appears homogeneous.

10. Filter the cells using a $100 \mu \mathrm{m}$ nylon cell strainer into a fresh sterile centrifuge tube.

11. Count the cells with a hemocytometer and plate 70,000 cells into $500 \mu \mathrm{l}$ of neuronal culture medium per well in a 24-well tissue culture plate. Agitate the wells left to right and incubate at $37^{\circ} \mathrm{C}$ in a humidified $5 \% \mathrm{CO}_{2}$ atmosphere $\left(\mathrm{CO}_{2}\right.$ incubator) for 14 days in vitro (DIV).

12. After 7 days, check the purity of neuronal cultures and, if glia cells are present, add cytosine $\beta$-D-arabinoside (Ara-C; $5 \mu \mathrm{M})$ to the wells to stop their proliferation. To do this, remove $250 \mu \mathrm{l}$ of neuronal culture medium (pH 7.4) from each well and add $250 \mu \mathrm{l}$ of fresh medium containing Ara-C. CAUTION! Ara-C is an irritant.

\section{Co-culture Preparation}

1. On day 11 of neuronal culture, coat a 6 -well plate with poly-D-lysine $(0.1 \mathrm{mg} / \mathrm{ml})$ under sterile conditions and incubate overnight at $37{ }^{\circ} \mathrm{C}$ in a humidified $5 \% \mathrm{CO}_{2}$ atmosphere $\left(\mathrm{CO}_{2}\right.$ incubator).

2. The following day (day 12 of neuronal culture), aspirate the excess poly-D-lysine and wash wells $2 x$ briefly and $2 x$ for 5 min with sterile water before adding fresh cell culture medium (without antibiotics) to coat the wells with a small amount of serum from the medium.

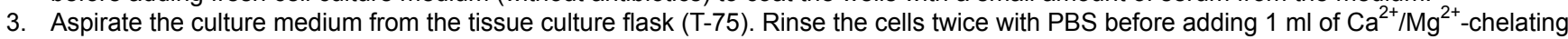
agent EDTA (0.48 mM) which gently and non-enzymatically dissociates cells. Agitate the cells to detach them from the bottom of the tissue flask.

4. Add $10 \mathrm{ml}$ of cell culture medium (without antibiotics as this may interfere with transfection), aspirate the cells and place in a sterile centrifuge tube. Pellet cells at $440 \times \mathrm{g}$ for 5 min using a low-speed bench-top centrifuge.

5. Remove the supernatant and resuspend the cells in $1 \mathrm{ml}$ of fresh cell culture medium. Using a hemocytometer, count the cells and plate at a density of $3 \times 10^{5}$ cells per well in a 6-well plate. Agitate gently and incubate for $24 \mathrm{hr}$ at $37^{\circ} \mathrm{C}$ in a humidified $5 \% \mathrm{CO}_{2}$ atmosphere $\left(\mathrm{CO}_{2}\right.$ incubator).

6. The following day (day 13 of neuronal culture) transiently transfect the HEK293 cells with mCherry cDNA in pcDNA3 expression construct using liposomal transfection reagent. Briefly, in a sterile microcentrifuge tube, add $500 \mu \mathrm{l}$ of reduced serum medium and $5 \mu \mathrm{g}$ of mCherry cDNA. Add $5 \mu \mathrm{l}$ of liposomal buffering reagent and gently mix before leaving at room temperature for $5 \mathrm{~min}$.

7. Add $8.75 \mu \mathrm{l}$ of liposomal transfection reagent and gently mix before leaving at room temperature for $30 \mathrm{~min}$. Pipette the contents of microcentrifuge tube up and down twice, transfer drop-wise to each well on the 6 -well tissue culture plate and incubate at $37^{\circ} \mathrm{C}$ in a humidified $5 \% \mathrm{CO}_{2}$ atmosphere $\left(\mathrm{CO}_{2}\right.$ incubator).

8. The following day (day 14 of neuronal culture), aspirate the HEK293 cell culture medium from each of the 6-wells and wash each well twice briefly with PBS $(\mathrm{pH} 7.4)$. Add $300 \mu \mathrm{l}$ of $\mathrm{Ca}^{2+} / \mathrm{Mg}^{2+}$-chelating agent EDTA $(0.48 \mathrm{mM})$ and $200 \mu \mathrm{l}$ of trypsin-EDTA (0.02 - $\left.0.48 \mathrm{mM}\right)$ solution to each well and incubate at $37^{\circ} \mathrm{C}$ for $5 \mathrm{~min}$.

9. Add $1 \mathrm{ml}$ of fresh HEK293 cell culture medium per well (this quenches the trypsin) and aspirate the detached cells into a sterile $15 \mathrm{ml}$ centrifuge tube. Centrifuge the cells at $440 \mathrm{xg}$ for $5 \mathrm{~min}$ at room temperature and remove the supernatant. Resuspend the pellet in $500 \mu \mathrm{l}$ of neuronal culture medium $(\mathrm{pH} 7.4)$. 
10. Using a hemocytometer, count the cells and seed at a density of 30,000 cells per well in a 24 -well tissue culture plate containing neurons. Agitate the plate to disperse the cells and incubate co-cultures at $37^{\circ} \mathrm{C}$ in a humidified $5 \% \mathrm{CO}_{2}$ atmosphere $\left(\mathrm{CO}_{2}\right.$ incubator) for $24 \mathrm{hr}$.

\section{Analysis of Synaptic Contacts and their Activity}

1. After $23 \mathrm{hr}$ in co-culture, investigate the formation of 'active' contacts between GABAergic medium spiny neurons and HEK293 cells using activity-dependent uptake of anti-synaptotagmin luminal domain-specific antibody conjugated with a fluorescent dye (Cy5, see Table 1). NOTE: The antibody will only gain access to the luminal domain of synaptotagmin, to which it binds when there is continuity between the synaptic vesicle lumen and extracellular space. This specifically occurs during neurotransmitter release, making this antibody an excellent marker of the active presynaptic terminals.

2. Firstly rinse the co-cultures with neuronal medium (Neurobasal A medium, $\mathrm{pH} 7.4$; see Table 1) and add Cy5-labeled mouse antisynaptotagmin antibody, diluted 1:50 in neuronal medium (Neurobasal A medium, pH 7.4), to the cultures, for 30 min. Incubate the cells during this time at $37^{\circ} \mathrm{C}$ in a humidified $5 \% \mathrm{CO}_{2}$ atmosphere $\left(\mathrm{CO}_{2}\right.$ incubator).

3. To remove the access of the antibody, wash the co-cultures briefly three times: first with cold normal PBS (pH 7.4), second with cold PBS ( $\mathrm{pH}$ 7.4) containing $200 \mathrm{mM} \mathrm{NaCl}$, and third with cold normal PBS ( $\mathrm{pH} \mathrm{7.4)}$

4. Fix the cells with $300 \mu \mathrm{l}$ of $4 \%$ paraformaldehyde/4\% sucrose in PBS (PFA, pH 7.4) for 10 min with agitation. Wash the cells briefly twice with PBS ( $\mathrm{pH} 7.4)$ then with two longer 10 min washes.

5. Add glycine $(0.3 \mathrm{M})$ to each well for 10 min with agitation to quench PFA.

6. Wash the cells briefly twice with PBS ( $\mathrm{pH} 7.4$ ) then with two longer $10 \mathrm{~min}$ washes before adding $300 \mu \mathrm{l}$ of blocking solution (1\% (w/v) bovine serum albumin (BSA) in PBS, pH 7.4) to reduce the non-specific binding of antibodies.

7. Aspirate the blocking solution and add the guinea pig anti-GABA $\mathrm{A}$ - $\mathrm{y} 2$ antibody directed against the $\mathrm{\gamma}^{2} \mathrm{~N}$-terminal domain ${ }^{33}(1: 3,000$ in $\mathrm{PBS}$, $\mathrm{pH} 7.4$ ) overnight at $4{ }^{\circ} \mathrm{C}$.

8. The following day, aspirate the primary antibody from the wells and wash the cells briefly twice with PBS then with two longer 10 min washes.

9. Permeabilize the cells using Triton $\mathrm{X}-100(0.1 \%)$ in blocking solution for $30 \mathrm{~min}$ at room temperature.

10. Wash the cells briefly twice with PBS ( $\mathrm{pH} \mathrm{7.4)} \mathrm{then} \mathrm{with} \mathrm{two} \mathrm{longer} 10$ min washes before adding either the mouse anti-glutamic acid decarboxylase (GAD) 65 antibody (1:4,000, Table 1) or the mouse anti-synapsin I antibody $(1: 1,000$, Table 1) for $120 \mathrm{~min}$ at room temperature.

11. Wash the cells briefly twice with PBS ( $\mathrm{pH} 7.4)$ then with two longer 10 min washes and then add blocking solution for 30 min at room temperature.

12. Centrifuge the appropriate secondary antibodies (typically goat anti-guinea pig IgG conjugated to Cy5, goat anti-mouse IgG conjugated to Alexa Fluor 488 or goat anti-mouse IgG Alexa Fluor 405, all at $2 \mu \mathrm{g} / \mathrm{ml}$ ) to remove aggregates of antibodies at $21,910 \times \mathrm{g}$ for $10 \mathrm{~min}$, and add antibodies (1:750) to blocking solution. Apply to appropriate wells for $1 \mathrm{hr}$ and cover with aluminum foil to protect the fluorophores from light exposure and consequent photobleaching.

13. Finally, wash the cells briefly twice with PBS (pH 7.4) then with two longer 10 min washes to remove any unbound secondary antibody and mount the coverslips using mounting reagent (Prolong Gold, Table 1) roughly $10 \mu \mathrm{l} \mathrm{per} \mathrm{coverslip.} \mathrm{Allow} 24 \mathrm{hr}$ to set at room temperature while protected from light before transferring to $4{ }^{\circ} \mathrm{C}$ for long term storage.

14. Analyze samples using a laser scanning confocal microscope with a $63 \mathrm{X}$ oil-immersion objective. Ensure the light levels and detector gain is adjusted to avoid saturation.

15. Observe potential synapse-like contacts as regions of co-localization between the presynaptic terminals positive for GAD65, synapsin I or Cy5-labelled anti-synaptotagmin and the postsynaptic HEK293 cells visualized by DIC or by the mCherry fluorescent indictor.

16. Count potential synapse-like contacts using Z-stack series of optical sections $(8-10)$ through a depth of $4-5 \mu \mathrm{m}$ per cell using the imaging software.

\section{Representative Results}

The protocol for this neuron-HEK293 cell co-culture model system has been finely tuned to allow optimal cell survival. In this system, formation of synapse-like contacts and their analysis relies on stable and consistent expression of all three $G_{A B A} R$ subunits which assemble into a functional receptor. It is therefore important to use immunocytochemical analysis to test for subunit expression at the surface of HEK293 cell before adding them to neuronal cultures. In these experiments, cell surface expression of $\alpha 1, \beta 2$ and $\gamma 2$ subunits (Figure 1A), or $\alpha 1, \beta 3$ and $\gamma 2$ subunits (Figure 1B), was detected using subunit-specific antibodies which bind to the extracellular epitopes of these subunits. A high degree of co-localization between these subunits at the HEK293 surface was demonstrated.

After confirming the surface expression and co-localization of $\mathrm{GABA}_{\mathrm{A}} \mathrm{R}$ subunits in HEK293 cells, co-cultures were prepared using HEK293 cells expressing $\alpha 1 / \beta 2 / \gamma 2 \mathrm{GABA}_{A} \mathrm{R}$ subunits and medium spiny neurons cultured for 14 days (14 days in vitro (DIV)). Cells in co-culture were incubated for $24 \mathrm{hr}$, fixed and analyzed using immunocytochemistry and confocal microscopy. Analysis of contacts indicated that GAD65-positive GABAergic axon terminals formed only sporadic contacts with the control HEK293 cells (Figure 2A, 2B). The number of contacts detected at 4 hr was $7.3 \pm 0.9$ per HEK293 cell, and this number was reduced to $5.5 \pm 0.5$ connections (mean \pm SEM) per HEK293 cell at 24 hr after adding HEK293 cells to the cultured neurons. In contrast, GAD65-positive GABAergic axon terminals formed numerous synapse-like contacts with HEK293 cells expressing GABA $A_{A}$ Rs. The number of contacts obtained at $4 \mathrm{hr}$ after adding HEK293 cells was $28.3 \pm 4.7$ per HEK293 cell, and this number was further increased to $52.1 \pm 6.3$ (mean \pm SEM) per HEK293 cell at $24 \mathrm{hr}$ in co-culture (Figure 2A, 2B).

To determine whether these synapse-like contacts were 'active,' i.e. supported vesicular transmitter release, a vesicle-luminal domain-specific anti-synaptotagmin Cy5-conjugated antibody was added to the co-culture medium after 23 hours of incubation. This antibody is only incorporated into presynaptic nerve terminals when a pore forms between the synaptic vesicle lumen and the extracellular fluid in the synaptic cleft during neurotransmitter release. Following release, the pore closes, leaving the synaptotagmin Cy5-conjugated fluorescent antibody attached to synaptotagmin inside the vesicle. In this way, only the vesicles actively engaged in neurotransmitter release are labeled with the antibody. In these experiments few if any contacts between the control HEK293 cells and the medium spiny neuron terminals were 'active' as shown by the lack of co-localization between the presynaptic GAD65/synaptotagmin fluorescence and mCherry fluorescence in HEK293 cells (Figure 3A). In 
contrast, many 'active' contacts were formed between the medium spiny neuron terminals and $\alpha 1 / \beta 2 / \gamma 2$-expressing HEK293 cells, as revealed by a high degree of co-localization between GAD65/synaptotagmin and mCherry, expressed specifically in HEK293 cells (Figure 3B).

To test whether a different subtype of $\mathrm{GABA}_{A} \mathrm{R}$ can also promote synapse-like formation in vitro, we have co-cultured $\alpha 1 / \beta 3 / \mathrm{Y} 2$ expressing HEK293 cells with medium spiny neurons. Again, control HEK293 cells rarely received contacts with synapsin-positive presynaptic terminals reaching $10.8 \pm 0.48$ (mean \pm SEM) contacts per HEK293 cell after $24 \mathrm{hr}$ in co-culture (Figure 4A left, 4B). However, HEK293 cells expressing $\alpha 1 / \beta 3 / y 2 G A B A_{A}$ Rs form significantly more synapse-like contacts with synapsin-positive presynaptic terminals of medium spiny neurons reaching $25.3 \pm 0.27$ (mean \pm SEM) contacts per HEK293 cell after $24 \mathrm{hr}$ in co-culture (Figure 4A right, 4B). This indicates that $\alpha 1 / \beta 3 / \mathrm{Y}^{2} \mathrm{GABA} \mathrm{A}_{\mathrm{A}} \mathrm{Rs}$ expressed in HEK293 cells are also able to promote synaptic contact formation, albeit their potency is lower than the potency of $\alpha 1 / \beta 2 / \mathrm{Y} 2-$ containing $\mathrm{GABA}_{\mathrm{A}} \mathrm{Rs}$.

These experiments indicate that the co-culture model system developed in our laboratory permits quantitative analysis of synaptic contact formation in vitro as well as evaluation of the efficacy of different subtypes of $G A B A_{A} R s$ in this process. These experiments further demonstrate that $\mathrm{GABA}_{A} \mathrm{Rs}$, in addition to being critical functional components of GABAergic synapses, may play a key role in the process of recognition and formation of synaptic contacts between inhibitory neurons and the appropriate neuronal target cells, independently of other synaptic adhesion proteins

A

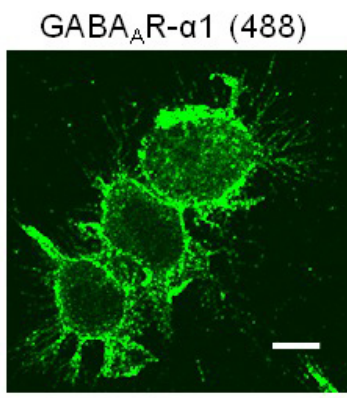

$\mathrm{GABA}_{\mathrm{A}} \mathrm{R}-\beta 2(555)$

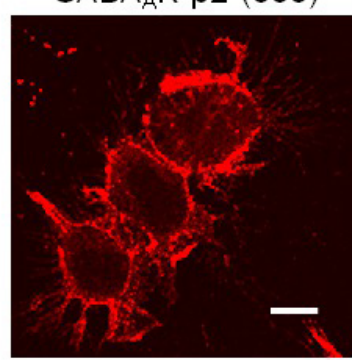

B

$\mathrm{GABA}_{\mathrm{A}} \mathrm{R}-\mathrm{a} 1(488)$
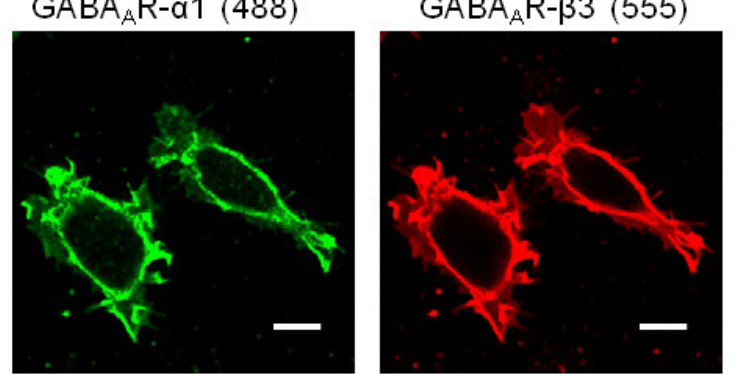
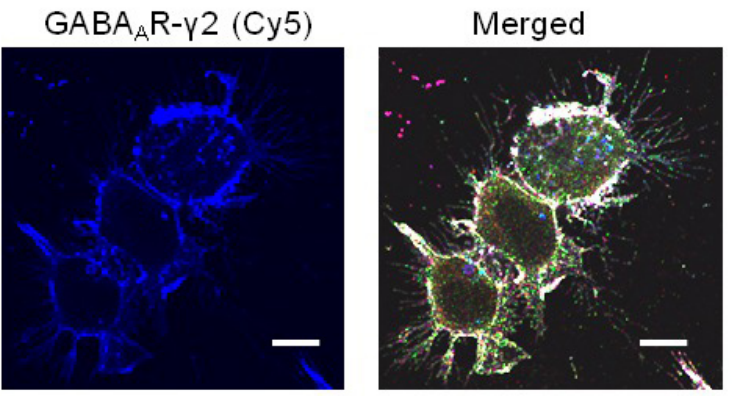

Figure 1. Immunocytochemical analysis of expression of $G_{A B A} R \alpha 1 / \beta 2 / Y 2$ or $\alpha 1 / \beta 3 / Y 2$ in stable HEK293 cell lines. Antibodies recognizing the extracellular domains of $\mathrm{GABA}_{A} \mathrm{R}$ subunits were used to label receptors expressed at the cell surface. (A) $\mathrm{HEK} 293$ cell line expressing a1 (Alexa Fluor 488), $\beta 2$ (Alexa Fluor 555) and $\gamma 2$ (Cy5) at high levels. (B) HEK293 cell line expressing a1 (Alexa Fluor 488 ), $\beta 2$ (Alexa Fluor 555) and ү2 (Су5) subunits at high levels. Scale bar: $10 \mu \mathrm{m}$. Please click here to view a larger version of this figure.
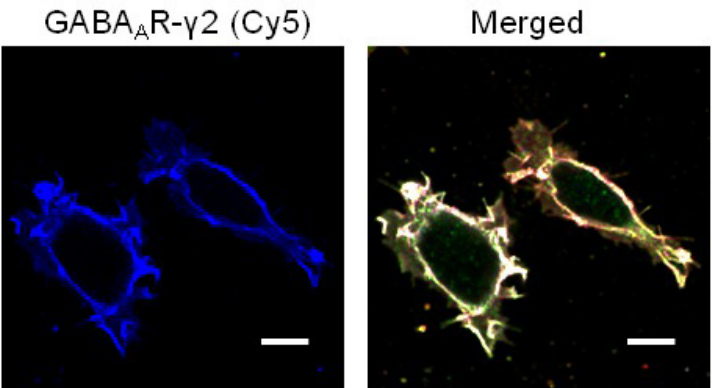
A
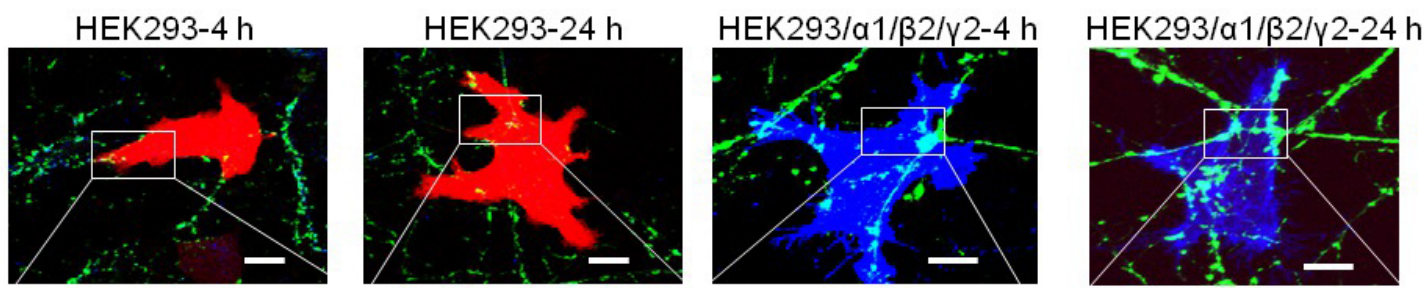

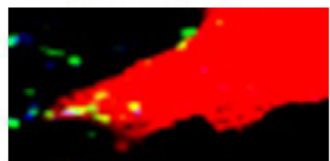

pcherry

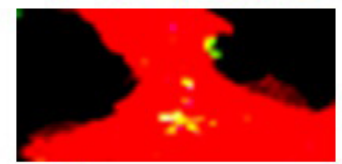

GAD65

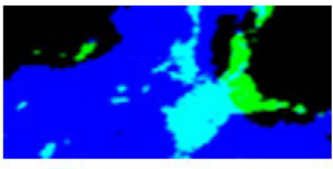

y2

B

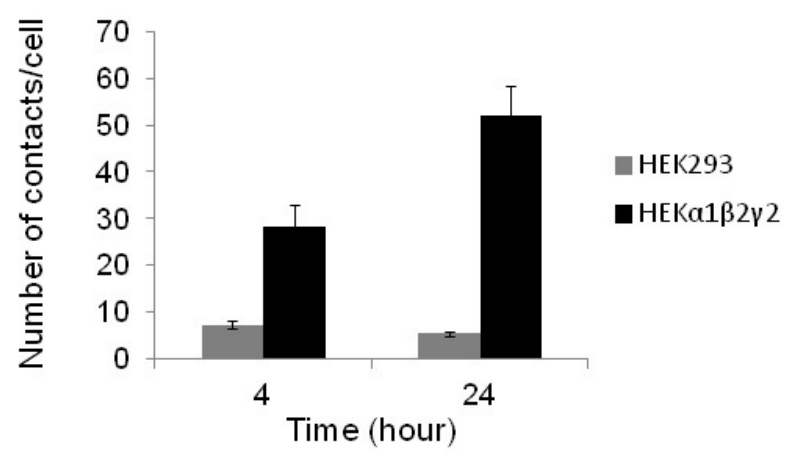

Figure 2. GABAergic medium spiny neurons form synapse-like contacts with $\alpha 1 / \beta 2 / y 2-$ expressing HEK293 cells in co-culture. (A) Fluorescent labeling of presynaptic terminals with anti-GAD65 antibodies (in green) and HEK293 cells with mCherry (in red, left) or the GABA $R$ Y2 subunit (in blue, right), revealed points of co-localization between these markers indicating formation of synapse-like contacts after 4 or 24 hr in co-culture. Scale bar: $10 \mu \mathrm{m}$. (B) Quantitative analysis of synapse-like contacts. HEK293 cells were identified based on their shape as revealed by DIC imaging and/or mCherry expression, and the number of contacts between GAD-65 positive puncta (in green) and the surface of HEK293 cells was counted by eye in each optical section of a Z-stack series ( $8-10)$ per cell using the imaging software, and expressed as the number of contacts/cell. The graph shows the number of contacts between medium spiny neurons and control HEK293 cells (light grey) or $\alpha 1 / \beta 2 /$ Y2-HEK293 cells(black) after 4 and $24 \mathrm{hr}$ in co-culture (mean \pm SEM, $n=8$ in each condition from two independent experiments). This figure has been modified from Fuchs et al. $(2013)^{30}$. Please click here to view a larger version of this figure. 
A: HEK293-pCherry
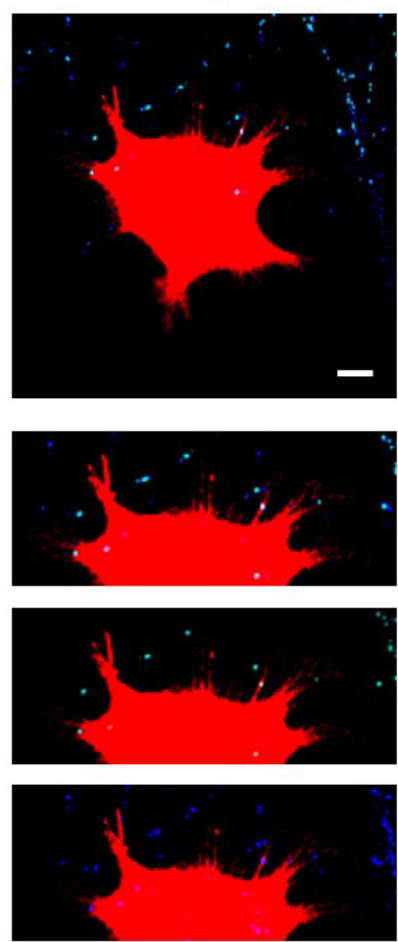

B: HEKa1/ß2//2-pCherry
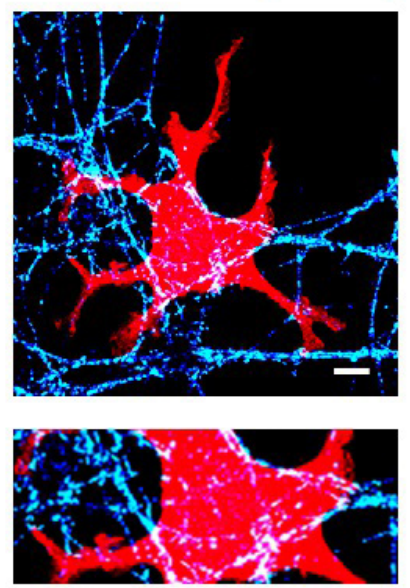

GAD65

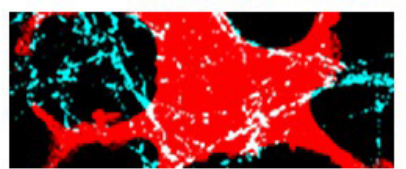

Synaptotagmin

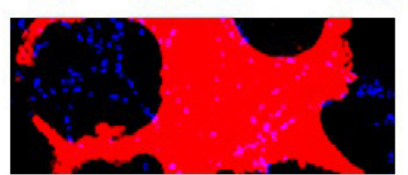

Figure 3. GABA ${ }_{A}$ Rs promote formation of active synaptic contacts. Immunolabeling of synapse-like contacts formed after 24 hours in coculture between medium spiny neuron terminals positive for GAD65 (Alexa Fluor 405 cyan) and (A) control HEK293 cells, or (B) HEK293- $1 /$ / 32 / Y2 cells, both transiently transfected with mCherry construct (red). Active contacts are identified by co-localization between the vesicle luminal domain-specific anti-synaptotagmin antibody (Cy5) and GAD65-specific antibody both in presynaptic terminals, and mCherry expressed in HEK293 cells. Scale bar: $10 \mu \mathrm{m}$. Please click here to view a larger version of this figure. 
A
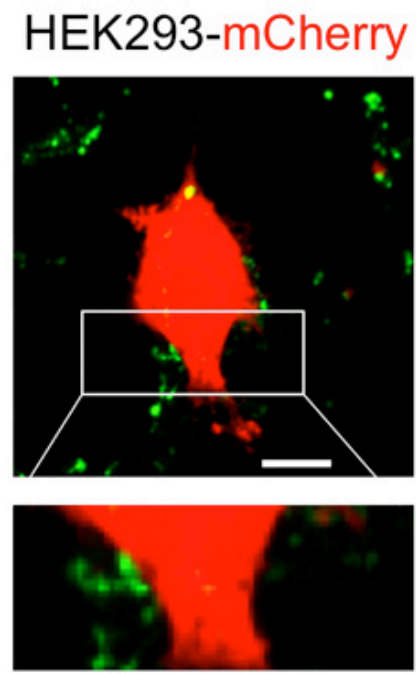

B:

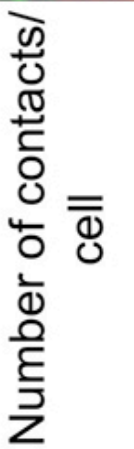

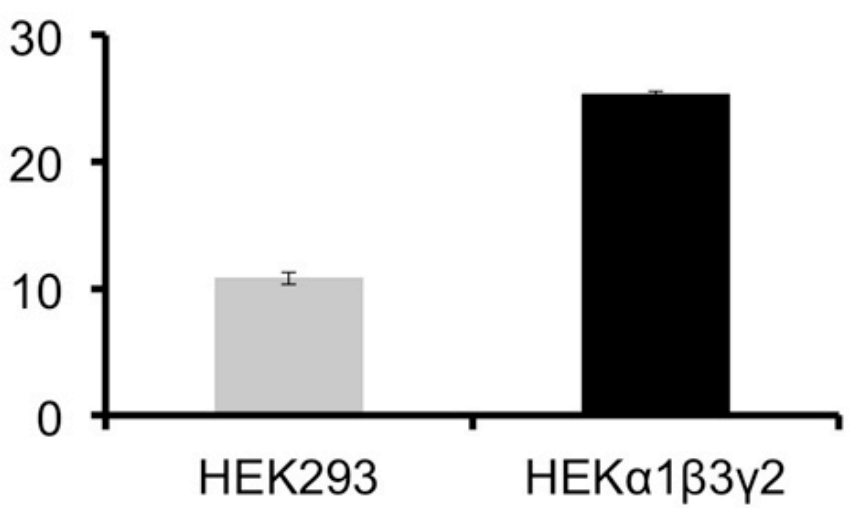

HEKa1/ß3/y2-mCherry
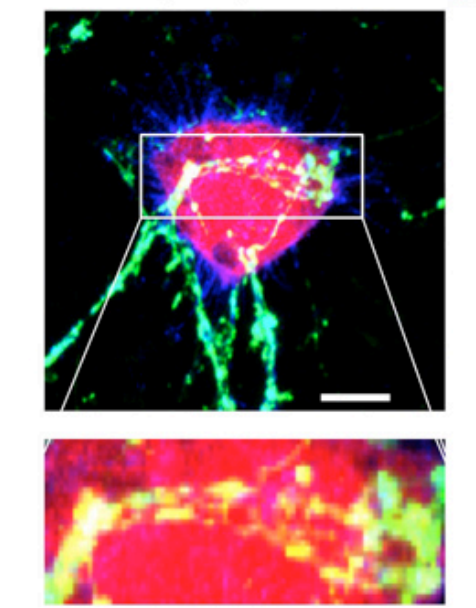

\section{(n)}

\section{.}

.

mCherry

Synapsin

y2 
compromises the successful analysis of contacts between HEK293 cells and neurons, because they become very rare. Conversely, adding too many HEK293 cells causes neuronal cell death within few hours.

Embryonic medium spiny neuron cultures should ideally be prepared using striatal tissue dissected from embryonic age 15 - 17 . However, it often happens that embryos are slightly younger or older than the optimal age. In this case, the number of neurons seeded in culture will need to be varied. Tissue that is younger than E15 may need to be seeded at a slightly lower density, whilst tissue that is older than E17 may need to be seeded at a higher density, to allow optimal cell survival. Furthermore, cytosine arabinoside (Ara-C) may need to be added to older cultures to prevent growth of glia, which is more abundant in older tissue.

When creating co-cultures, it is important to plate the optimized number of transfected HEK293 or $\alpha 1 / \beta 2 / Y 2$ HEK293 expressing cells, as mentioned above. However, it may be necessary to determine this for each individual cell line, because of differences in their survival. Typically 30,000 cells in a maximum volume of $50 \mu$ should be added to each well of a 24-well dish, which already contains $500 \mu l$ of neuronal culture medium, as this ensures that the conditioned neuronal medium is not diluted too much and that the conditions within each well remain fairly constant, e.g. the concentration of growth factors. Adding volumes greater than $50 \mu$ lo each well would generally kill the neurons.

One of the major disadvantages of the co-culture technique is that the neuronal cultures are created from dissociated cells grown as a monolayer, which means that the neurons have been removed from their normal microenvironment and are unable to establish their normal anatomical organization. Therefore they lack the appropriate connections, inputs and secreted molecules from other cells that may influence the initial stages of synapse development. For example, in vivo medium spiny neurons are densely innervated by glutamatergic inputs from the cortex, thalamus and other brain regions ${ }^{34}$, however, in our neuronal cultures glutamatergic synapses do not form because these inputs are damaged during dissection of the striatal tissue. How the absence of functional glutamatergic synapses in cultured medium spiny neurons

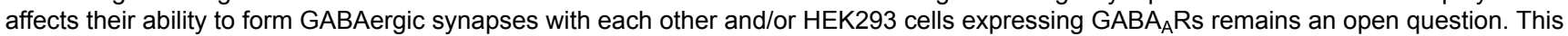
question could be easily addressed by culturing medium spiny neurons together with cortical glutamatergic neurons thereby allowing them to form functional synapses ${ }^{35}$ prior to the addition of HEK293 cells. An alternative approach would be to design a co-culture model system based on organotypic slice cultures, which maintain some of the cytoarchitecture which may be important for maturation and synapse formation. However, organotypic slice cultures have dense and heterogeneous neuropil which can compromise the analysis performed here. Another important disadvantage of using co-culture assays is that $\mathrm{GABA}_{\mathrm{A}}$ Rs expressed at the surface of HEK293 cells are not clustered as they are in neurons, although this appears not to be necessary for synapse formation given a high enough surface expression ${ }^{30}$. For example, in the rodent brain and in hippocampal cultures, the $\alpha 1 G \mathrm{GBA}_{A} R$ subunit is found in most GABAergic synapses on all postsynaptic domains of pyramidal cells. However, the $\alpha 2$ is specifically located in a subset of synapses on the somata and dendrites but is highly enriched in the axon initial segment, as revealed by immunofluorescence and electron microscopy ${ }^{36}$. Given that synapse formation in the co-cultures can still be reliably detected and analyzed ${ }^{30}$, this suggests that the density of $\mathrm{GABA}_{\mathrm{A}}$ Rs at the cell surface of HEK293 cells may be similar to, or even higher than the density of these receptors within synaptic clusters in neurons. This can explain, at least in part, why synaptic adhesion proteins, such as neuroligin, and postsynaptic density proteins, such as gephyrin, are not necessary for synapse formation in the co-cultures, if the appropriately assembled $\mathrm{GABA}_{\mathrm{A}} \mathrm{Rs}$ are present at sufficient density.

It is well documented that $\mathrm{GABA}_{A} \mathrm{Rs}$ are structurally and functionally heterogeneous, and that the receptor subunit composition determines their subcellular localization and pharmacological properties. For example, incorporation of the 2 subunits is known to be a prerequisite for the synaptic localization of $G_{A B A}$ Rs while the subunit is almost exclusively present in extrasynaptic GABA $A_{A}$. The receptors that incorporate only $\alpha \beta$ combinations are also thought to be predominantly localized to the extrasynaptic domains ${ }^{12-14}$. Whether this specificity is maintained in our co-culture system can be easily tested by transiently transfecting 2 or subunit cDNAs into HEK293 cell lines stably expressing $\alpha$ and $\beta$ subunits, before adding them to neuronal cultures. Our preliminary experiments using this approach have suggested that synaptic contacts are readily formed only in the presence of the 2 subunit, indicating that the specificity observed in vivo is likely to be preserved in vitro (data not shown).

Furthermore, $G A B A_{A}$ Rs incorporating different $\alpha$ subunits are selectively localized to synaptic contacts formed with specific types of presynaptic neurons. For example, in the globus pallidus, the $\alpha 1-G A B A_{A}$ Rs are generally found at striatopallidal (str-GP) and palliopallidal (GP-GP) synapses, which are located on dendrites and somatic regions of the medium spiny neurons, respectively. The $\alpha 3-G A B A_{A} R s$ are located in perisomatic regions of medium spiny neurons and are contacted by local GP axon collaterals, whilst the $\alpha 2-G A B A_{A} R_{s}$ are located on distal dendrites of these neurons and contacted primarily by inputs from the striatum ${ }^{32}$. Expression of specific $\alpha$ subunits in different types of synapses and in different neuronal compartments has also been demonstrated in other brain areas such as hippocampus ${ }^{21}$ and neocortex ${ }^{18,20}$. These findings raise the question as to how the specific inhibitory synapses are formed in the brain. Does the adhesion of a specific type of presynaptic terminal induce the insertion of specific $G A B A_{A} R$ subtypes into the points of contact? Are the receptors trafficked to specific subcellular locations according to their subunit composition, where their plasma membrane insertion is a prerequisite for the adhesion of axonal terminals of specific origin? To date, these questions remain unanswered. The use of reduced model systems such as the co-culture model system, allow us to start answering this complex questions because the system is easily amenable to transfection of DNA constructs and application of reagents and, importantly, it is suitable for live cell imaging analysis ${ }^{30}$. Thus, using this model system we can start testing the role of individual molecules, including different types of $\mathrm{GABA}_{\mathrm{A}} \mathrm{Rs}$, known to be present at synaptic contacts. Another advantage is that synapses in this model system form rapidly, within minutes to hours, reducing the duration of experiments. Similar co-culture model systems were successfully employed in the past to screen for the novel synaptogenic molecules ${ }^{27,37,38}$.

Understanding how the central nervous system develops, matures and forms connections between neurons so intricately to control, for example, behavior or cognition, is of fundamental importance. This distant aim will only be achieved by delineating the molecular mechanisms that govern the individual steps of recognition and cell-to-cell communication during development. Due to sheer complexity, the molecular details of these multiple cellular interactions can currently be studied with precision only in reduced systems. However, the ability to increase the complexity of these systems by expressing multiple combinations of proteins and studying how they interact has some advantages in comparison with, for example, genetic deletion approaches. This is because the accurate interpretation of the effects of a single gene deletion is often compromised by changes associated with compensatory mechanisms masking the effects of original lesions, particularly in the developing brain. The simple yet informative co-culture technique described here has allowed a discovery of the structural role of GABA $\mathrm{A}_{\mathrm{A}}$ in synapse formation and opened a possibility to investigate how $\mathrm{GABA}_{\mathrm{A}}$ Rs and other cell adhesion molecules and/or synaptic matrix proteins interact with each other during synaptogenesis. Synaptic matrix proteins are of particular interest given that they have recently been demonstrated to play a key role in glutamatergic synapse formation ${ }^{39}$. Further development of co-culture models is important because they have the potential to advance 
our knowledge of the molecular mechanisms which guide the 'normal' brain development and thus increase our understanding of how these mechanisms are altered in many neurodevelopmental diseases, such as epilepsy, schizophrenia, autism spectrum disorders and many others.

\section{Disclosures}

The authors declare that they have no competing financial interests.

\section{Acknowledgements}

We would like to acknowledge financial support from the MRC UK (G0800498). We would also like to thank Professor J-M Fritschy, University of Zurich, for providing the GABA $A-R$ subunit-specific $\gamma 2$ antibody and Professor R. Harvey, UCL School of Pharmacy, for providing the pcDNA $3.1^{(+)}$expression vectors containing antibiotic resistance genes for production of stably transfected HEK293 cell lines.

\section{References}

1. Wang, D. D., \& Kriegstein, A. R. Defining the role of GABA in cortical development. J Physiol. 587, 1873-1879, doi:10.1113/ jphysiol.2008.167635, (2009).

2. Ben-Ari, Y., Khalilov, I., Kahle, K. T., \& Cherubini, E. The GABA excitatory/inhibitory shift in brain maturation and neurological disorders. The Neuroscientist : a review journal bringing neurobiology, neurology and psychiatry. 18, 467-486, doi:10.1177/1073858412438697, (2012).

3. Sieghart, W. Structure, pharmacology, and function of GABAA receptor subtypes. Adv Pharmacol. 54, 231-263, (2006).

4. Unwin, N. Neurotransmitter action: opening of ligand-gated ion channels. Cell. 72 Suppl, 31-41, (1993).

5. Homanics, G. E. et al. Mice devoid of gamma-aminobutyrate type A receptor beta3 subunit have epilepsy, cleft palate, and hypersensitive behavior. Proceedings of the National Academy of Sciences of the United States of America. 94, 4143-4148, (1997).

6. Gunther, U. et al. Benzodiazepine-insensitive mice generated by targeted disruption of the gamma 2 subunit gene of gamma-aminobutyric acid type A receptors. Proceedings of the National Academy of Sciences of the United States of America. 92, 7749-7753, (1995).

7. Mohler, H. GABA(A) receptor diversity and pharmacology. Cell Tissue Res. 326, 505-516, doi:10.1007/s00441-006-0284-3, (2006).

8. Low, K. et al. Molecular and neuronal substrate for the selective attenuation of anxiety. Science. 290, 131-134, (2000).

9. Rudolph, U. et al. Benzodiazepine actions mediated by specific gamma-aminobutyric acid(A) receptor subtypes. Nature. 401, 796-800, doi:10.1038/44579, (1999).

10. Rudolph, U., \& Knoflach, F. Beyond classical benzodiazepines: novel therapeutic potential of GABAA receptor subtypes. Nat Rev Drug Discov. 10, 685-697, doi:10.1038/nrd3502, (2011).

11. Hulst, C., Atack, J. R., \& Kooy, R. F. The complexity of the GABAA receptor shapes unique pharmacological profiles. Drug Discov Today. 14, 866-875, doi:10.1016/j.drudis.2009.06.009, (2009)

12. Essrich, C., Lorez, M., Benson, J. A., Fritschy, J. M., \& Luscher, B. Postsynaptic clustering of major GABAA receptor subtypes requires the gamma 2 subunit and gephyrin. Nat Neurosci. 1, 563-571, doi:10.1038/2798, (1998).

13. Schweizer, C. et al. The gamma 2 subunit of GABA(A) receptors is required for maintenance of receptors at mature synapses. Mol Cell Neurosci. 24, 442-450, (2003).

14. Belelli, D. et al. Extrasynaptic GABAA receptors: form, pharmacology, and function. The Journal of neuroscience : the official journal of the Society for Neuroscience. 29, 12757-12763, doi:10.1523/JNEUROSCI.3340-09.2009, (2009).

15. Connolly, C. N., Wooltorton, J. R., Smart, T. G., \& Moss, S. J. Subcellular localization of gamma-aminobutyric acid type A receptors is determined by receptor beta subunits. Proceedings of the National Academy of Sciences of the United States of America. 93, 9899-9904, (1996).

16. Connolly, C. N., Krishek, B. J., McDonald, B. J., Smart, T. G., \& Moss, S. J. Assembly and cell surface expression of heteromeric and homomeric gamma-aminobutyric acid type A receptors. J Biol Chem. 271, 89-96, (1996).

17. Klausberger, T., Roberts, J. D., \& Somogyi, P. Cell type- and input-specific differences in the number and subtypes of synaptic GABA(A) receptors in the hippocampus. The Journal of neuroscience : the official journal of the Society for Neuroscience. 22, 2513-2521, doi:20026228, (2002).

18. Thomson, A. M., \& Jovanovic, J. N. Mechanisms underlying synapse-specific clustering of GABA(A) receptors. Eur J Neurosci. 31, 2193-2203, doi:10.1111/j.1460-9568.2010.07252.x, (2010).

19. Fritschy, J. M., Panzanelli, P., \& Tyagarajan, S. K. Molecular and functional heterogeneity of GABAergic synapses. Cell Mol Life Sci. 69, 2485-2499, doi:10.1007/s00018-012-0926-4, (2012).

20. Ali, A. B., \& Thomson, A. M. Synaptic alpha 5 subunit-containing GABAA receptors mediate IPSPs elicited by dendrite-preferring cells in rat neocortex. Cereb Cortex. 18, 1260-1271, doi:10.1093/cercor/bhm160, (2008).

21. Thomson, A. M., Bannister, A. P., Hughes, D. I., \& Pawelzik, H. Differential sensitivity to Zolpidem of IPSPs activated by morphologically identified CA1 interneurons in slices of rat hippocampus. Eur J Neurosci. 12, 425-436, (2000).

22. Nyiri, G., Freund, T. F., \& Somogyi, P. Input-dependent synaptic targeting of alpha(2)-subunit-containing GABA(A) receptors in synapses of hippocampal pyramidal cells of the rat. Eur J Neurosci. 13, 428-442, (2001).

23. Treutlein, B., Gokce, O., Quake, S. R., \& Sudhof, T. C. Cartography of neurexin alternative splicing mapped by single-molecule long-read mRNA sequencing. Proceedings of the National Academy of Sciences of the United States of America. 111, E1291-1299, doi:10.1073/ pnas.1403244111, (2014).

24. Siddiqui, T. J., \& Craig, A. M. Synaptic organizing complexes. Current opinion in neurobiology. 21, 132-143, doi:10.1016/j.conb.2010.08.016, (2011).

25. Tanaka, H. et al. Higher-order architecture of cell adhesion mediated by polymorphic synaptic adhesion molecules neurexin and neuroligin. Cell reports. 2, 101-110, doi:10.1016/j.celrep.2012.06.009, (2012).

26. Krueger, D. D., Tuffy, L. P., Papadopoulos, T., \& Brose, N. The role of neurexins and neuroligins in the formation, maturation, and function of vertebrate synapses. Current opinion in neurobiology. 22, 412-422, doi:10.1016/j.conb.2012.02.012, (2012). 
27. Scheiffele, P., Fan, J., Choih, J., Fetter, R., \& Serafini, T. Neuroligin expressed in nonneuronal cells triggers presynaptic development in contacting axons. Cell. 101, 657-669, (2000).

28. Graf, E. R., Zhang, X., Jin, S. X., Linhoff, M. W., \& Craig, A. M. Neurexins induce differentiation of GABA and glutamate postsynaptic specializations via neuroligins. Cell. 119, 1013-1026, doi:10.1016/j.cell.2004.11.035, (2004).

29. Dong, N., Qi, J., \& Chen, G. Molecular reconstitution of functional GABAergic synapses with expression of neuroligin-2 and GABAA receptors. Mol Cell Neurosci. 35, 14-23, doi:10.1016/j.mcn.2007.01.013, (2007).

30. Fuchs, C. et al. GABA(A) receptors can initiate the formation of functional inhibitory GABAergic synapses. Eur J Neurosci. 38, 3146-3158, doi:10.1111/ejn.12331, (2013).

31. Ventimiglia, R., \& Lindsay, R. Culturing nerve cells: Rat striatal neurons in low-density, serum-free culture. 2nd edn, 371-393, MIT Press (1998).

32. Gross, A. et al. Differential localization of $\operatorname{GABA}(\mathrm{A})$ receptor subunits in relation to rat striatopallidal and pallidopallidal synapses. Eur $J$ Neurosci. 33, 868-878, doi:10.1111/j.1460-9568.2010.07552.x, (2011).

33. Fritschy, J. M., \& Mohler, H. GABAA-receptor heterogeneity in the adult rat brain: differential regional and cellular distribution of seven major subunits. J Comp Neurol. 359, 154-194, doi:10.1002/cne.903590111, (1995).

34. Doig, N. M., Moss, J., \& Bolam, J. P. Cortical and thalamic innervation of direct and indirect pathway medium-sized spiny neurons in mouse striatum. The Journal of neuroscience : the official journal of the Society for Neuroscience. 30, 14610-14618, doi:10.1523/ JNEUROSCI.1623-10.2010, (2010).

35. Lalchandani, R. R., \& Vicini, S. Inhibitory collaterals in genetically identified medium spiny neurons in mouse primary corticostriatal cultures. Physiological reports. 1, e00164, doi:10.1002/phy2.164, (2013).

36. Nusser, Z., Sieghart, W., Benke, D., Fritschy, J. M., \& Somogyi, P. Differential synaptic localization of two major gamma-aminobutyric acid type A receptor alpha subunits on hippocampal pyramidal cells. Proceedings of the National Academy of Sciences of the United States of America. 93, 11939-11944, (1996).

37. Linhoff, M. W. et al. An unbiased expression screen for synaptogenic proteins identifies the LRRTM protein family as synaptic organizers. Neuron. 61, 734-749, doi:10.1016/j.neuron.2009.01.017, (2009).

38. Pettem, K. L., Yokomaku, D., Takahashi, H., Ge, Y., \& Craig, A. M. Interaction between autism-linked MDGAs and neuroligins suppresses inhibitory synapse development. J Cell Biol. 200, 321-336, doi:10.1083/jcb.201206028, (2013).

39. Wit, J. et al. Unbiased discovery of glypican as a receptor for LRRTM4 in regulating excitatory synapse development. Neuron. 79, 696-711, doi:10.1016/j.neuron.2013.06.049, (2013). 